\section{Case Reports in Neurology}

Case Rep Neurol 2021;13:123-130

DOI: $10.1159 / 000512275$
Published online: February 16, 2021

(C) 2021 The Author(s)

Published by S. Karger AG, Basel www.karger.com/crn

This article is licensed under the Creative Commons Attribution-NonCommercial 4.0 International License (CC BY-NC) (http://www.karger.com/Services/OpenAccessLicense). Usage and distribution for commercial purposes requires written permission.

\title{
R1352Q CACNA1A Variant in a Patient with Sporadic Hemiplegic Migraine, Ataxia, Seizures and Cerebral Oedema: A Case Report
}

\author{
Anker Stubberud ${ }^{a, b} \quad$ Emer O'Connor $^{a, c} \quad$ Erling Tronvik ${ }^{b, d}$ \\ Henry Houlden ${ }^{c}$ Manjit Matharu ${ }^{a}$ \\ aHeadache and Facial Pain Group, UCL Queen Square Institute of Neurology and National \\ Hospital for Neurology and Neurosurgery, London, UK; ${ }^{b}$ Department of Neuromedicine \\ and Movement Sciences, NTNU Norwegian University of Science and Technology, \\ Trondheim, Norway; 'Department of Neuromuscular Disorders, UCL Queen Square \\ Institute of Neurology, Queen Square, London, UK; dDepartment of Neurology, St. Olavs \\ Hospital, Trondheim, Norway
}

\section{Keywords}

Ataxia $\cdot$ Encephalopathy $\cdot$ Migraine

\begin{abstract}
Mutations in the CACNA1A gene show a wide range of neurological phenotypes including hemiplegic migraine, ataxia, mental retardation and epilepsy. In some cases, hemiplegic migraine attacks can be triggered by minor head trauma and culminate in encephalopathy and cerebral oedema. A 37-year-old male without a family history of complex migraine experienced hemiplegic migraine attacks from childhood. The attacks were usually triggered by minor head trauma, and on several occasions complicated with encephalopathy and cerebral oedema. Genetic testing of the proband and unaffected parents revealed a de novo heterozygous nucleotide missense mutation in exon 25 of the CACNA1A gene (c.4055G>A, p.R1352Q). The R1352Q CACNA1A variant shares the phenotype with other described CACNA1A mutations and highlights the interesting association of trauma as a precipitant for hemiplegic migraine. Subjects with early-onset sporadic hemiplegic migraine triggered by minor head injury or associated with seizures, ataxia or episodes of encephalopathy should be screened for
\end{abstract}

Anker Stubberud
Department of Neuromedicine and Movement Sciences
NTNU Norwegian University of Science and Technology
Edvard Griegs Gate 8, NO-7030 Trondheim (Norway)
anker.stubberud@ntnu.no




\section{Case Reports in Neurology}

Case Rep Neurol 2021;13:123-130

\begin{tabular}{l|l}
\hline DOI: 10.1159/000512275 & ๑ 2021 The Author(s). Published by S. Karger AG, Basel \\
\hline
\end{tabular} www.karger.com/crn

Stubberud et al.: R1352Q CACNA1A Variant in Sporadic Hemiplegic Migraine

mutations. These patients should also be advised to avoid activities that may result in head trauma, and anticonvulsants should be considered as prophylactic migraine therapy.

(C) 2021 The Author(s)

Published by S. Karger AG, Basel

\section{Introduction}

Familial hemiplegic migraine (FHM) is a rare autosomal dominant variant of migraine with an aura characterized by motor weakness. FHM is divided into three subtypes depending on which gene is affected, and the most common mutation is located in the CACNA1A (OMIM 601011) gene on chromosome 19p13 (FHM1) [1]. Hemiplegic migraine sufferers without a family history of hemiplegic migraine are classified as cases of sporadic hemiplegic migraine (SHM). SHM may be caused by one of the genetic mutations that cause FHM; however, mutations are rarely found in SHM, especially in adult-onset cases [1-3]. Genetic analyses are therefore recommended only in early-onset SHM cases, especially when associated with other neurologic deficits $[1,3]$.

Besides hemiplegic migraine, CACNA1A mutations are associated with spinocerebellar ataxia 6 and episodic ataxia type $2[4,5]$. In addition, a more severe phenotype with earlyonset ataxia, development delays, seizures and episodes of hemiplegia and cerebral oedema triggered by minor head trauma, fever or other exogenous stress has more recently been described [5, 6]. Such episodes can be severe, last for months, and lead to disability or even death. We present a case of early-onset SHM with attacks triggered by minor head trauma and complicated by encephalopathy and cerebral oedema in which a rarely reported CACNA1A mutation was found.

\section{Case Report}

A 37-year-old male was first seen at the tertiary Headache Centre at the National Hospital for Neurology and Neurosurgery, UK, in September 2013 due to complex hemiplegic migraine. He was born to healthy non-consanguineous parents following an unremarkable pregnancy and perinatal course. His brother suffered from migraine, but otherwise there was no family history suggestive of hemiplegic migraine, neurological diseases or cerebellar syndromes. He failed to meet developmental milestones at 6 and 12 months of age and was subsequently diagnosed with athetoid cerebral palsy in a setting of hypotonia. During childhood, he exhibited signs of cerebellar ataxia, global development delay and mild intellectual disability. He experienced his first generalized tonic-clonic seizure at the age of 3 years following a mild head trauma at school, when a toddler hit his head with a toy car. This resulted in a coma and massive cerebral oedema requiring ICU admission and treatment with mannitol. During childhood he had several similar episodes of seizure-associated encephalopathy, for which no cause was found. None of these subsequent episodes resulted in cerebral oedema. He also experienced episodes of petit mal seizures. An EEG at the age of 13 years showed a sharp focus on the left temporal region. Notably, a muscle biopsy showed no evidence of mitochondrial disease.

From the age of 7 years he started suffering from headaches. The episodes usually started with difficulty using the arm or leg followed by a facial drop on one side, blurred vision and

\section{Karger'=}




\section{Case Reports in Neurology}

Case Rep Neurol 2021;13:123-130

DOI: 10.1159/000512275

Stubberud et al.: R1352Q CACNA1A Variant in Sporadic Hemiplegic Migraine

slurred speech. The visual and speech symptoms lasted for approximately $90 \mathrm{~min}$ and were succeeded by a severe headache lasting from 2 days to a few weeks. The hemiparesis persisted during the headache, associated with photophobia and motion sensitivity. Initially he had 23 episodes per year, but this increased to 4 annually in his teenage years. All episodes were associated with mild head trauma or minor illness, usually viral infections.

He was at the time of referral taking Calcichew and alendronic acid for fracture of the femur and paracetamol for his headaches. Neurological examinations revealed slurred speech, slow tongue movements with brisk jaw jerk, hypotonia, pathologically brisk reflexes and an extensor plantar reflex on the right. There was no ataxia or nystagmus during examination at the headache centre.

Because of the hemiplegic attacks complicated by minor head trauma, and the episodes of encephalopathy during childhood, a severe CACNA1A mutation was suspected and a series of investigations including genetic testing was initiated. Neuropsychological testing revealed verbal and non-verbal scores in the impaired ranges, with a verbal IQ of 52 and a performance IQ of 55. MRI of the brain and cervical spine showed marked cerebellar hemispheric and vermian atrophy (Fig. 1). The neurophysiological studies were unremarkable. Even though a CACNA1A mutation was suspected, whole genome sequencing was carried out on the patient and both parents, as a part of the 100,000 Genomes Project (Genomics England). The patient had not undergone genetic testing prior to the sequencing. Segregation analysis identified a de novo missense mutation in exon 25 of CACNA1A (c.4055G>A, p.R1352Q). This mutation was absent in his parents. His brother was not tested for the mutation. Figure 2 indicates the location of the mutation in the protein. The mutation was located in a highly conserved region of the protein (online Supplementary Material; for all online suppl. material, see www.karger.com/doi/10.1159/000512275) and SIFT [7] and PolyPhen [8] scores indicated a deleterious and damaging effect of the mutation.

The patient continues to have approximately one hemiplegic migraine attack yearly, often triggered by episodes such as falling or hitting his head. He also has episodes of hemiplegic migraine in the absence of minor head trauma, but has not had episodes of encephalopathy or cerebral oedema since childhood. He keeps himself fit and active, regularly going to the gym and golfing, and is currently functioning well in a part-time job and has attended college for adult education and life skill classes. He is advised to strictly avoid activities that involve any risk of trauma to the head and is using naproxen $500 \mathrm{mg}$ with good effect on migraine aura and pain.

\section{Discussion}

The CACNA1A gene encodes the pore-forming $\alpha$-1A subunit of neuronal voltage-dependent $\mathrm{P} / \mathrm{Q}$-type calcium channels, which is important in mediating fast synaptic transmission at central and peripheral nerve terminals $[1,4]$. It is hypothesized that changed calcium ion influx through the channel reduces the threshold for the cortical spreading depressions leading to motor aura and hemiplegic migraine attacks $[1,9]$. The calcium channels are also present in the cerebellum, where they maintain the highly regular, intrinsic pacemaking of Purkinje cells, likely explaining the associated ataxia [10]. On the other hand, episodes of cerebral oedema seem to occur in some CACNA1A mutations where there is an increased risk of a cytotoxic oedematous response to minor brain injury. This is thought to be mediated through ionic perturbations and cytotoxic release of excitatory neurotransmitters because of the

\section{Karger'=}




\section{Case Reports in Neurology}

Case Rep Neurol 2021;13:123-130

DOI: $10.1159 / 000512275$

(c) 2021 The Author(s). Published by S. Karger AG, Basel www.karger.com/crn

Stubberud et al.: R1352Q CACNA1A Variant in Sporadic Hemiplegic Migraine

dysfunctional calcium channels and mechanical strain-induced activation of these channels $[6,9]$. Even though the pathophysiological evidence for cerebral oedema mostly stems from the S218L mutation, it is conceivable that the same pathophysiological mechanisms apply for other CACNA1A mutations.

This report and similar cases of CACNA1A mutations illustrate some important points for the clinical care of patients with severe forms of SHM. The de novo R1352Q variant presented in this case has, to the best of our knowledge, been reported in only two other publications $[11,12]$. The phenotype presented in these reports is almost identical to that of the present case; both cases displayed widespread and serious neurological symptoms including global development delay, ataxia and recurring episodes of hemiplegia and/or coma triggered by mild head injury. One of these reports points out the overlap between $C A C N A 1 A$-related ataxia and migraine [11]. Moreover, de novo pathogenic CACNA1A mutations seem to occur much more frequently in early-onset cases of SHM [3], whereas the proportion of mutations amongst adult-onset patients is low [1]. CACNA1A-related disorders should therefore be considered in early-onset ataxia or SHM [5, 11]. Interestingly, there is also a report of a R1350Q variant, resulting in a nearly identical phenotype in a 7-year-old boy with mental retardation, cerebral ataxia and recurrent episodes of coma following mild head trauma [13]. Next, there seems to be a genetic link between epilepsy and hemiplegic migraine that is of relevance to the R1352Q mutation. In a meta-analysis of 30 CACNA1A variants, 10 were associated with seizures, 7 of which were located in the transmembrane domains [14]. Two of these variants (R1346Q and R1349Q) were located in the same transmembrane domain (III S4) of the calcium channel as the R1352Q variant (Fig. 2). The R1346Q mutation has been described in 5 families, all with hemiplegic migraine and ataxia [14], whilst the R1349Q mutation has been described in 2 case reports of SHM, both of which presented with episodes of cerebral oedema $[2,15]$. The patient presented in this case report did in fact have seizures since childhood, and it appears that patients with mutations in the transmembrane III or IV S4/5 domains are more susceptible to developing epilepsy [14]. Finally, one of the more extensively studied CACNA1A mutations is the S218L variant $[1,16]$. This variant also results in a phenotype with episodes of encephalopathy and cerebral oedema following head trauma, and sometimes ataxia or intellectual disability. Altogether, these cases illustrate the usefulness of screening for mutations in FHM-related genes in patients with early-onset SMH that is triggered by minor head trauma or associated with ataxia, seizures or encephalopathy. The authors suggest that screening should be focused, selecting a panel of neuronal channel genes associated with FHM and SHM.

In the case report of the R1349Q mutation, an emergency treatment protocol consisting of combined corticosteroids and administration of a hypertonic solution was established [15]. Such a treatment regime of intracranial hypertension management and corticosteroids has also proven to be effective in other cases [5]. The treatment regime was not attempted during episodes of cerebral oedema in the patient we present here, but it is warranted in future episodes. In addition, there are some reports of acetazolamide reducing the frequency of hemiplegic episodes complicated by cerebral oedema [5]. Also, considering the genetic link between migraine and epilepsy, researchers recommended that clinicians prescribe antiepileptic drugs, such as topiramate, to hemiplegic migraine patients with mutations with a marked susceptibility for epileptic seizures [14]. Topiramate would indeed have been a valid option if the present patient had had an attack frequency justifying preventive treatment.

To conclude, we report a de novo missense CACNA1A mutation, R1352Q, in a patient suffering from SHM in the UK. This is one of the many CACNA1A variants leading to severe hemiplegic migraine complicated by cerebral oedema. As recommended in the literature, screening

\section{Karger'=}




\section{Case Reports in Neurology}

\begin{tabular}{|c|c|}
\hline \multicolumn{2}{|c|}{ Case Rep Neurol 2021;13:123-130 } \\
\hline DOI: 10.1159/000512275 & $\begin{array}{l}\text { (c) } 2021 \text { The Author(s). Published by S. Karger AG, Basel } \\
\text { www.karger.com/crn }\end{array}$ \\
\hline
\end{tabular}

for mutations in FHM genes should be done amongst patients with early-onset SHM which is triggered by minor head injury or associated with seizures, ataxia or episodes of encephalopathy. Moreover, clinicians should counsel patients with hemiplegic migraine triggered by minor head injury to avoid activities that may precipitate attacks, have an emergency treatment protocol ready for episodes of cerebral oedema, and consider anticonvulsants as migraine prophylaxis.

\section{Acknowledgements}

The authors thank the patient for consent to the publication of this article.

\section{Statement of Ethics}

Written informed consent was obtained from the patient for publication of this case report, accompanying images and genetic sequencing.

\section{Conflict of Interest Statement}

The authors declared no potential conflicts of interest with respect to the research, authorship and/or publication of this article.

\section{Funding Sources}

The authors received no financial support for the research, authorship and/or publication of this article.

\section{Author Contributions}

A.S.: interpretation of data, and drafting and revision of the manuscript; E.0.: interpretation of data, and drafting and revision of the manuscript; E.T., H.H. and M.M.: study concept, interpretation of data and manuscript revision.

\section{References}

1 Russell MB, Ducros A. Sporadic and familial hemiplegic migraine: pathophysiological mechanisms, clinical characteristics, diagnosis, and management. Lancet Neurol. 2011 May;10(5):457-70.

2 Malpas TJ, Riant F, Tournier-Lasserve E, Vahedi K, Neville BG. Sporadic hemiplegic migraine and delayed cerebral oedema after minor head trauma: a novel de novo CACNA1A gene mutation. Dev Med Child Neurol. 2010 Jan;52(1):103-4.

3 Riant F, Ducros A, Ploton C, Barbance C, Depienne C, Tournier-Lasserve E. De novo mutations in ATP1A2 and CACNA1A are frequent in early-onset sporadic hemiplegic migraine. Neurology. 2010 Sep;75(11):967-72.

\section{Karger'"}




\section{Case Reports in Neurology}

\begin{tabular}{l|l}
\hline Case Rep Neurol 2021;13:123-130 \\
\hline DOI: 10.1159/000512275 & $\begin{array}{l}\text { @ 2021 The Author(s). Published by S. Karger AG, Basel } \\
\text { www.karger.com/crn }\end{array}$ \\
\hline
\end{tabular}

Stubberud et al.: R1352Q CACNA1A Variant in Sporadic Hemiplegic Migraine

4 Ducros A, Denier C, Joutel A, Cecillon M, Lescoat C, Vahedi K, et al. The clinical spectrum of familial hemiplegic migraine associated with mutations in a neuronal calcium channel. N Engl J Med. 2001 Jul;345(1):17-24.

5 Gauquelin L, Hawkins C, Tam EW, Miller SP, Yoon G. Pearls \& Oy-sters: fatal brain edema is a rare complication of severe CACNA1A-related disorder. Neurology. 2020 Apr;94(14):631-4.

6 Kors EE, Terwindt GM, Vermeulen FL, Fitzsimons RB, Jardine PE, Heywood P, et al. Delayed cerebral edema and fatal coma after minor head trauma: role of the CACNA1A calcium channel subunit gene and relationship with familial hemiplegic migraine. Ann Neurol. 2001 Jun;49(6):753-60.

7 Ng PC, Henikoff S. SIFT: predicting amino acid changes that affect protein function. Nucleic Acids Res. 2003 Jul;31(13):3812-4.

8 Adzhubei IA, Schmidt S, Peshkin L, Ramensky VE, Gerasimova A, Bork P, et al. A method and server for predicting damaging missense mutations. Nat Methods. 2010 Apr;7(4):248-9.

9 Kaja S, Van de Ven RC, Broos LA, Frants RR, Ferrari MD, Van den Maagdenberg AM, et al. Severe and progressive neurotransmitter release aberrations in familial hemiplegic migraine type 1 Cacna1a S218L knock-in mice. J Neurophysiol. 2010 Sep;104(3):1445-55.

10 Pietrobon D. CaV2.1 channelopathies. Pflugers Arch. 2010 Jul;460(2):375-93.

11 Travaglini L, Nardella M, Bellacchio E, D'Amico A, Capuano A, Frusciante R, et al. Missense mutations of CACNA1A are a frequent cause of autosomal dominant nonprogressive congenital ataxia. Eur J Paediatr Neurol. 2017 May;21(3):450-6.

12 Ramdas S, Murugan V, Castle B, Thomas NH, Whitney A. A new mutation on the CACNA1A gene in familial hemiplegic migraine and delayed cerebral oedema: 99. Dev Med Child Neurol. 2009;S1:64.

13 Blumkin L, Michelson M, Leshinsky-Silver E, Kivity S, Lev D, Lerman-Sagie T. Congenital ataxia, mental retardation, and dyskinesia associated with a novel CACNA1A mutation. J Child Neurol. 2010 Jul;25(7): 892-7.

14 Prontera P, Sarchielli P, Caproni S, Bedetti C, Cupini LM, Calabresi P, et al. Epilepsy in hemiplegic migraine: genetic mutations and clinical implications. Cephalalgia. 2018 Feb;38(2):361-73.

15 Camia F, Pisciotta L, Morana G, Schiaffino MC, Renna S, Carrera P, et al. Combined early treatment in hemiplegic attacks related to CACNA1A encephalopathy with brain oedema: blocking the cascade? Cephalalgia. 2017 Oct;37(12):1202-6.

16 Debiais S, Hommet C, Bonnaud I, Barthez MA, Rimbaux S, Riant F, et al. The FHM1 mutation S218L: a severe clinical phenotype? A case report and review of the literature. Cephalalgia. 2009 Dec;29(12):1337-9. 
Case Reports in Neurology
Case Rep Neurol 2021;13:123-130 DOI: $10.1159 / 000512275$ (c) The Author(s). Published by S. Karger AG, Basel Stubberud et al.: R1352Q CACNA1A Variant in Sporadic Hemiplegic Migraine

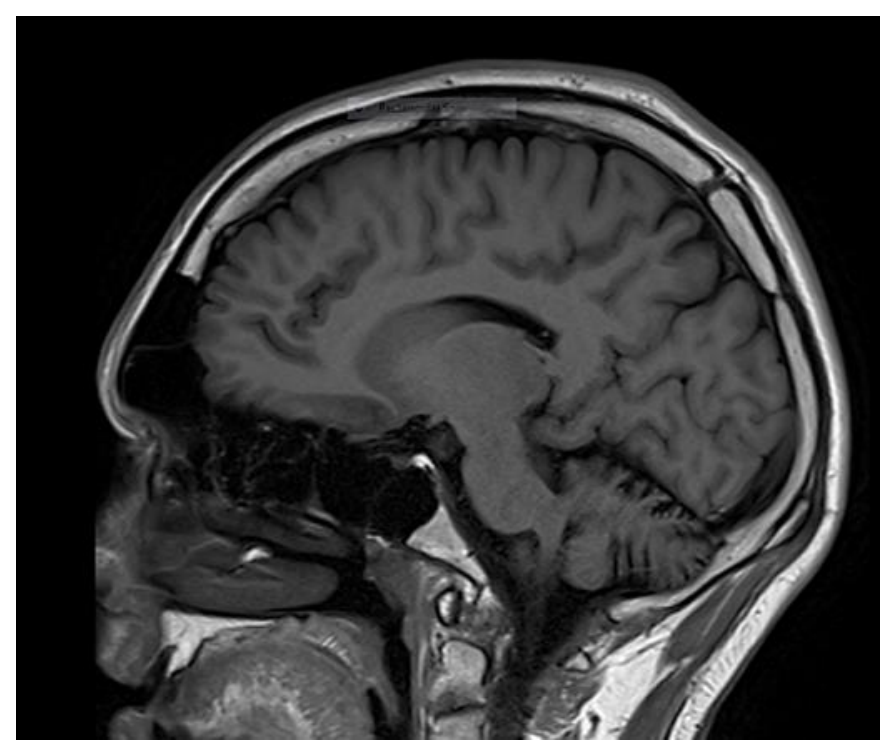

Fig. 1. Sagittal T1-weighted brain MRI scan showing marked cerebellar atrophy. There were no intrinsic cerebellar lesions, the brainstem was well preserved, and there was normal preservation of both cerebral hemispheres. 


\section{Case Reports in Neurology}
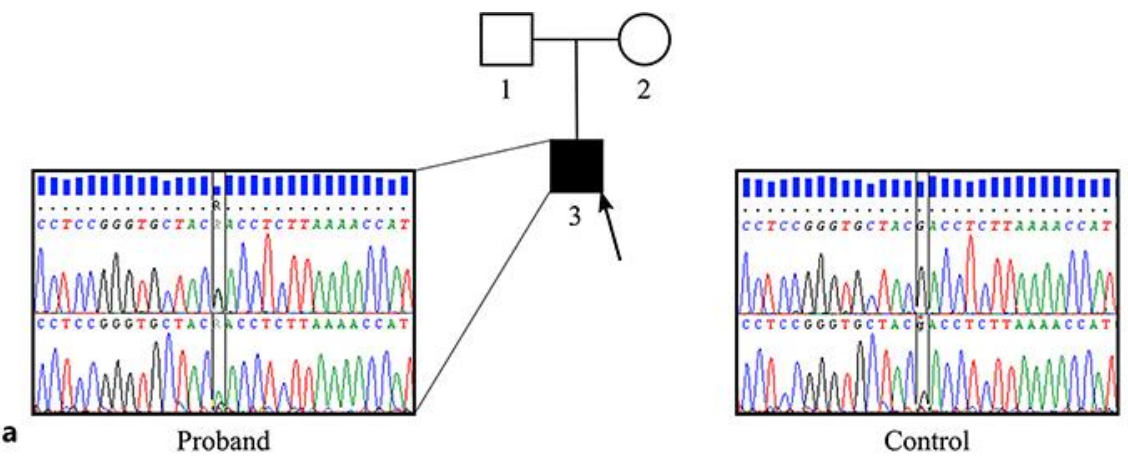

I

II

III

Control

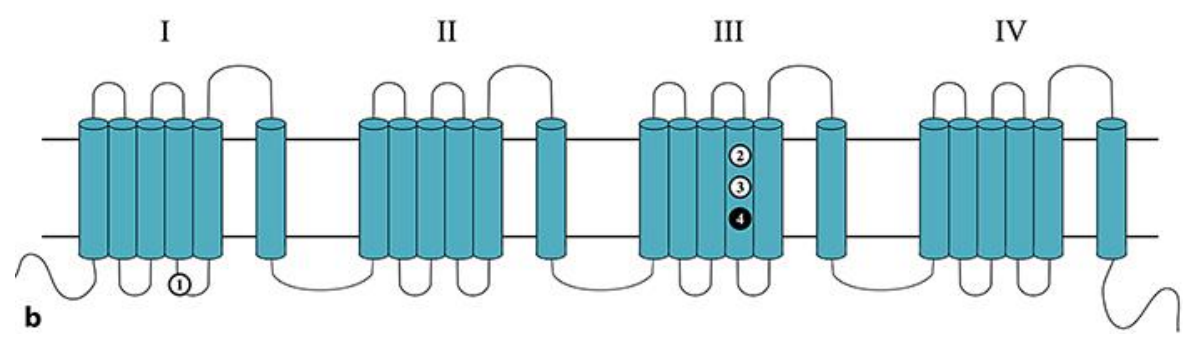

Fig. 2. a Pedigree and sequencing results. Males and females are indicated by squares and circles, respectively. Black filled figures indicate the hemiplegic phenotype. The arrow marks the proband (3). Sequencing of the proband showed a de novo heterozygous missense R1352Q mutation seen as a decreased height of the chromatogram between the two vertical lines. The mutation was not present in the proband's parents $(1,2)$. $\mathbf{b}$ Schematic presentation of the protein structure of the calcium channel encoded by CACNA1A. The black numbered circle (4) represents the novel de novo R1352Q mutation found in in the fourth segment of the third transmembrane domain. The white numbered circles show the locations of other CACNA1A mutations described in this paper. The S218L mutation is located intracellularly in the first domain (1), and the R1346Q and R1349Q mutations $(2,3)$ are both located in the same segment as the R1352Q variant. 